\title{
INDANYL ANALOGS AS POTENTIAL ANTIMICROBIAL AGENTS
}

\author{
SUDIP KUMAR MANDAL*
}

Department of Pharmaceutical Chemistry, Faculty of Pharmacy, Dr. B. C. Roy College of Pharmacy \& Allied Health Sciences, Durgapur, West Bengal, India. Email: gotosudip79@gmail.com

Received: 05 January 2018, Revised and Accepted: 30 January 2018

ABSTRACT

Objective: The wide variety of biological activities of different indane derivatives makes them an interesting moiety in the field of medicinal chemistry. The objective of the study was to identify and develop novel antimicrobial agents from indanyl analogs.

Methods: Recently synthesized indanyl analogs (4a-c and 5a-o) were examined against various pathogenic microorganisms (Gram-positive and Gram-negative bacteria and fungi) using serial dilution method. These analogs were found to possess antibacterial and antifungal activities with minimum inhibitory concentration values ranging between 1.56 and $100 \mu \mathrm{g} / \mathrm{mL}$.

Results: The results revealed that the entire compounds showed mild-to-moderate antibacterial activities and moderate-to-excellent antifungal activities against the pathogenic microorganisms as compared to the standard drugs ciprofloxacin and fluconazole, respectively. Compounds $4 \mathrm{a}$, $5 \mathrm{a}$, $5 b, 5 d, 5 e, 5 i$, and $5 \mathrm{j}$ exhibited antifungal activities superior to the reference drug.

Conclusion: Based on the structure-activity relationship, it can conclude that the indan-3-oxo-1-acetic acid moiety is essential for the activities and lipophilic alkoxy substituents on indane ring have enhanced the biological activity. Further, structure-activity relationship studies of the compounds $4 \mathrm{a}, 5 \mathrm{a}$, and $5 \mathrm{~b}$ are needful to find the new lead as antimicrobial agent.

Keywords: Indanyl analogs, Minimum inhibitory concentration, Antibacterial, Antifungal.

(C) 2018 The Authors. Published by Innovare Academic Sciences Pvt Ltd. This is an open access article under the CC BY license (http://creativecommons. org/licenses/by/4. 0/) DOI: http://dx.doi.org/10.22159/ajpcr.2018.v11i5.24635

\section{INTRODUCTION}

The growing incidence of microbial resistance to currently used antibiotics represents a serious medical problem. Therefore, there is an urgentneed to developnew classes of therapeuticagents to treatmicrobial infections. Indanyl derivatives have already drawn some attention as one of the templates for synthesizing compounds of varying biological activities such as antimicrobial [1-7], antitubercular [8-10], antimalarial [11], anti-inflammatory [12-16], anticancer 1 [17,18], antiviral [19], monoamine oxidase inhibitor [20], and anti-Alzheimer [21]. In search of newer antimicrobial agents, I have discovered and evaluated a series of substituted indanyl acids [(5-ethoxy-6-methoxy-3-oxo-2,3-dihydro-1Hinden-l-yl)acetic acid, (5,6-dimethoxy-3-oxo-2,3-dihydro-1H-inden-l-yl) acetic acid, and (6-chloro-3-oxo -2, 3-dihydro-1H-inden-l-yl) acetic acid] and their esters [(5-ethoxy-6-methoxy-3-oxo-2,3-dihydro-1H-inden-lyl)acetic acid esters, (5,6-dimethoxy-3-oxo-2,3-dihydro-1H-inden-l-yl) acetic acid esters, and (6-chloro-3-oxo -2, 3-dihydro-1H-inden-l-yl) acetic acid esters] against various pathogenic microorganisms.

\section{EXPERIMENTAL}

\section{Materials and methods}

Substituted Indan-3-oxo-1-aceticacids (4a-c) and the corresponding esters (5a-o), outlined in Fig. 1, were synthesized as described earlier $[15,16]$. Strains used were procured from the microbial type culture collection (MTCC), Institute of Microbial Technology, Chandigarh, and National Chemical Laboratory, Pune, India.

\section{Antimicrobial studies}

The in vitro antibacterial activities of the synthesized compounds (4ac and 5a-o) were carried out against various bacterial strains, such as Gram-positive bacteria Staphylococcus aureus (NCIM 2901) and Bacillus subtilis (MTCC441) and Gram-negative bacteria Escherichia coli (MTCC 2810), Pseudomonas aeruginosa (NCIM 2036), Salmonella typhi (NCIM 2501) and Klebsiella pneumoniae (MTCC 3384) by serial dilution method [22,23]. The synthesized compounds were evaluated for various antibacterial activities with MIC values ranging between 1.56 and $100 \mu \mathrm{g} / \mathrm{mL}$. Ciprofloxacin was used as a standard drug for antibacterial activity of the synthesized compounds.

The synthesized compounds (4a-c and 5a-o) were also screened for their in vitro antifungal activity against Candida albicans (MTCC 227) and Aspergillus niger (NCIM 1056) by serial dilution method [24,25]. The compounds were tested with minimum inhibitory concentration (MIC) values ranging between 6.25 and $50 \mu \mathrm{g} / \mathrm{mL}$ for various antifungal activities. The activity of each compound was compared with fluconazole as standard.

MICs were determined to evaluate the antimicrobial activity of synthesized compounds [26,27]. A pure culture of a single microorganism was grown in Mueller-Hinton broth (MHB). The antimicrobial agents were diluted a number of times, 1:1, through a sterile diluents (MHB). Test compounds were dissolved in $10 \%$ dimethyl sulfoxide, to produce a $2000 \mathrm{~g} / \mathrm{mL}$ stock solution. These test tubes were serially diluted to give a concentration of $100,50,25,12.5,6.25,3.125,1.56$, and $0.78 \mu \mathrm{g} / \mathrm{mL}$. MHB was used for bacteria and Sabouraud dextrose broth was used for fungus. The cell density of each inoculum was adjusted in sterile water of a McFarland standard. A final concentration was $\sim 107 \mathrm{CFU} / \mathrm{mL}$ and $\sim 106 \mathrm{CFU} / \mathrm{mL}$ for bacteria and fungi, respectively. Microbial inoculums were added to the two-fold diluted samples. The test tubes were incubated $18-24 \mathrm{~h}$ at $37^{\circ} \mathrm{C} \pm 1^{\circ} \mathrm{C}$ for bacteria and $2-5$ days at $25^{\circ} \mathrm{C} \pm 1^{\circ} \mathrm{C}$ for fungi. The highest dilution of the test compound that completely inhibited the growth of test organism was considered as the MIC value of the test compound and was expressed in $\mu \mathrm{g} / \mathrm{mL}$.

\section{RESULTS AND DISCUSSION}

\section{Antimicrobial studies}

Antibacterial activities

Marketed antimicrobials have various drawbacks such as toxicity and narrow spectrum of activity and few of them show drug-drug interactions. 
Table 1: MIC of test compounds (4a-c and 5a-o) against S. aureus, B. subtilis, S. typhi, E. coli, P. aeruginosa, and K. pneumoniae

\begin{tabular}{|c|c|c|c|c|c|c|}
\hline \multirow[t]{2}{*}{ Compound } & \multicolumn{6}{|c|}{$\mathrm{MIC}(\mu \mathrm{g} / \mathrm{mL})$} \\
\hline & S. aureus & B. subtilis & S. typhi & E. coli & P. aeruginosa & K. pneumoniae \\
\hline $4 a$ & 1.56 & 1.56 & 6.25 & 6.25 & 6.25 & 3.125 \\
\hline $5 a$ & 6.25 & 1.56 & 6.25 & 25 & 6.25 & 3.125 \\
\hline $5 b$ & 6.25 & 1.56 & 6.25 & 6.25 & 12.5 & 6.25 \\
\hline $5 c$ & 3.125 & 6.25 & 1.56 & 6.25 & 12.5 & 1.56 \\
\hline $5 d$ & 6.25 & 50 & 6.25 & 12.5 & 50 & 12.5 \\
\hline $5 e$ & 12.5 & 6.25 & 6.25 & 12.5 & 6.25 & 3.125 \\
\hline $4 b$ & 25 & 25 & 25 & 25 & 25 & 25 \\
\hline $5 f$ & 6.25 & 12.5 & 1.56 & 12.5 & 3.125 & 12.5 \\
\hline $5 \mathrm{~g}$ & 6.25 & 12.5 & 6.25 & 50 & 12.5 & 50 \\
\hline $5 \mathrm{~h}$ & 50 & 25 & 25 & 25 & 25 & 25 \\
\hline $5 \mathrm{i}$ & 50 & 25 & 25 & 50 & 25 & 12.5 \\
\hline $5 j$ & 12.5 & 12.5 & 12.5 & 12.5 & 12.5 & 12.5 \\
\hline $4 c$ & 12.5 & 12.5 & 12.5 & 50 & 100 & 100 \\
\hline $5 \mathrm{k}$ & 25 & 50 & 25 & 25 & 50 & 25 \\
\hline 51 & 6.25 & 6.25 & 3.125 & 6.25 & 3.125 & 3.125 \\
\hline $5 \mathrm{~m}$ & 25 & 12.5 & 25 & 50 & 12.5 & 100 \\
\hline $5 n$ & 12.5 & 12.5 & 12.5 & 12.5 & 12.5 & 12.5 \\
\hline 50 & 12.5 & 12.5 & 12.5 & 50 & 100 & 100 \\
\hline Ciprofloxacin & 0.78 & 0.78 & 0.78 & 0.78 & 0.78 & 0.78 \\
\hline
\end{tabular}

MIC: Minimum inhibitory concentration, S. aureus: Staphylococcus aureus, B. subtilis: Bacillus subtilis, E. coli: Escherichia coli, P. aeruginosa: Pseudomonas aeruginosa, S. typhi: Salmonella typhi, K. pneumonia: Klebsiella pneumonia

Table 2: MIC of test compounds (4a-c and 5a-o) against C. albicans and A. niger

\begin{tabular}{lcc}
\hline \multirow{2}{*}{ Compound } & \multicolumn{2}{c}{ MIC $(\boldsymbol{\mu g} / \mathbf{m L})$} \\
\cline { 2 - 3 } & C. albicans & A. niger \\
\hline 4a & 6.25 & 6.25 \\
$5 \mathrm{a}$ & 6.25 & 6.25 \\
$5 \mathrm{~b}$ & 6.25 & 6.25 \\
$5 \mathrm{c}$ & 12.5 & 12.5 \\
$5 \mathrm{~d}$ & 12.5 & 6.25 \\
$5 \mathrm{e}$ & 6.25 & 6.25 \\
4b & 12.5 & 12.5 \\
$5 \mathrm{f}$ & 25 & 50 \\
$5 \mathrm{~g}$ & 12.5 & 12.5 \\
$5 \mathrm{~h}$ & 25 & 50 \\
$5 \mathrm{i}$ & 12.5 & 6.25 \\
$5 \mathrm{j}$ & 6.25 & 12.5 \\
$4 \mathrm{c}$ & 25 & 25 \\
$5 \mathrm{k}$ & 12.5 & 12.5 \\
$5 \mathrm{l}$ & 25 & 12.5 \\
$5 \mathrm{~m}$ & 50 & 25 \\
$5 \mathrm{n}$ & 12.5 & 12.5 \\
$5 \mathrm{o}$ & 12.5 & 50 \\
Fluconazole & 12.5 & 12.5 \\
\hline
\end{tabular}

MIC: Minimum inhibitory concentration, C. albicans: Candida albicans, A. niger: Aspergillus niger

Demands for new antimicrobial agents with a broad spectrum of activity and less adverse effects have been increased, due to the high incidence of infections in immunocompromised patients. Most of the tested compounds (4a-c and 5a-o) exhibited mild to moderately good in vitro antibacterial activity against both the Gram-positive ( $S$. aureus and $B$. subtilis) and the Gram-negative (E. coli, P. aeruginosa, S. typhi, and $K$. pneumonia) bacteria. The antibacterial data indicated that compounds $5 e, 5 f$, and $5 \mathrm{l}$ exhibited moderate and compounds $4 \mathrm{a}, 5 \mathrm{a}, 5 \mathrm{~b}$, and $5 \mathrm{c}$ illustrated appreciable antibacterial activity against various strains but lower than that of standard ciprofloxacin. Among the synthesized series, 4 a showed the overall best activity and the highest inhibition against $S$. aureus and B. subtilis and $5 c$ showed the highest inhibition against $S$. typhi and K. pneumoniae. Compounds $4 \mathrm{a}$ and $5 \mathrm{c}$ both contain ethoxy and methoxy groups in 5 and 6 positions of the indan-3-oxo-1-acetic acid moiety, respectively, though 1 position of $5 c$ was esterified by n-propyl alcohol. Results of antibacterial studies have been presented in Table 1.

\begin{tabular}{|c|c|c|c|c|c|c|c|}
\hline & & & & $\mathrm{C}_{\mathrm{OR}}^{\mathrm{O}}$ & & & \\
\hline Compound & $\mathrm{R}_{1}$ & $\mathbf{R}_{2}$ & $\mathbf{R}$ & Compound & $\mathrm{R}_{1}$ & $\mathbf{R}_{2}$ & $\mathbf{R}$ \\
\hline $4 a$ & $\mathrm{OCH}_{3}$ & $\mathrm{OC}_{2} \mathrm{H}_{5}$ & $\mathrm{H}$ & $5 g$ & $\mathrm{OCH}_{3}$ & $\mathrm{OCH}_{3}$ & Et \\
\hline $4 b$ & $\mathrm{OCH}_{3}^{3}$ & $\mathrm{OCH}_{3}{ }^{\mathrm{S}}$ & $\mathrm{H}$ & $5 \mathrm{~h}$ & $\mathrm{OCH}_{3}^{3}$ & $\mathrm{OCH}_{3}^{3}$ & $\operatorname{Pr}$ \\
\hline $4 c$ & $\mathrm{Cl}^{3}$ & $\mathrm{H}^{3}$ & $\mathrm{H}$ & $5 i$ & $\mathrm{OCH}_{3}^{3}$ & $\mathrm{OCH}_{3}^{3}$ & i-Pr \\
\hline $5 a$ & $\mathrm{OCH}_{3}$ & $\mathrm{OC}_{2} \mathrm{H}_{5}$ & $\mathrm{Me}$ & $5 j$ & $\mathrm{OCH}_{3}^{3}$ & $\mathrm{OCH}_{3}^{3}$ & $\mathrm{Bu}$ \\
\hline $5 b$ & $\mathrm{OCH}_{3}^{3}$ & $\mathrm{OC}_{2}^{2} \mathrm{H}_{5}^{5}$ & $\mathrm{Et}$ & $5 \mathrm{k}$ & $\mathrm{Cl}^{3}$ & $\mathrm{H}^{3}$ & $\mathrm{Me}$ \\
\hline $5 c$ & $\mathrm{OCH}_{3}$ & $\mathrm{OC}_{2} \mathrm{H}_{5}$ & $\operatorname{Pr}$ & 51 & $\mathrm{Cl}$ & $\mathrm{H}$ & Et \\
\hline $5 d$ & $\mathrm{OCH}_{3}^{3}$ & $\mathrm{OC}_{2}^{2} \mathrm{H}_{5}^{5}$ & i-Pr & $5 \mathrm{~m}$ & $\mathrm{Cl}$ & $\mathrm{H}$ & $\operatorname{Pr}$ \\
\hline $5 e$ & $\mathrm{OCH}_{3}^{3}$ & $\mathrm{OC}_{2}^{2} \mathrm{H}_{5}^{5}$ & $\mathrm{Bu}$ & $5 n$ & $\mathrm{Cl}$ & $\mathrm{H}$ & i-Pr \\
\hline $5 f$ & $\mathrm{OCH}_{3}^{3}$ & $\mathrm{OCH}_{3}{ }^{3}$ & $\mathrm{Me}$ & 50 & $\mathrm{Cl}$ & $\mathrm{H}$ & $\mathrm{Bu}$ \\
\hline
\end{tabular}

Fig. 1: Indan-1-acetic acids and their ester derivatives

\section{Antifungal activities}

Antifungal activities of all compounds (4a-c and 5a-o) were evaluated against $C$. albicans and A. niger. Most of the compounds exhibited moderate-to-excellent antifungal activities. Among the synthesized compounds, 4b, 5c,5g, 5k, 5l, and 5n showed comparable antifungal activities and $4 a, 5 a, 5 b, 5 d, 5 e, 5 i$, and $5 j$ showed higher antifungal activities than fluconazole. Hence, these compounds were found to be potent antifungal agents. Few of the tested compounds $4 \mathrm{c}, 5 \mathrm{f}, 5 \mathrm{~h}, 5 \mathrm{~m}$, and $5 \mathrm{n}$ showed less inhibition against the microorganisms as compared to the standard drug. Majority of the tested compounds showed comparable to high in vitro antifungal activities, contain alkoxy groups in 5 and 6 positions of the indane moiety, which has accounted for their enhanced activity. Results of antibacterial studies have been presented in Table 2 .

\section{CONCLUSION}

Substituted indanyl acids (4a-c) and esters (5a-o) were investigated for their in vitro antibacterial and antifungal activities by well plate method. Among the screened samples, $4 \mathrm{a}, 5 \mathrm{a}, 5 \mathrm{~b}$, and $5 \mathrm{c}$ illustrated appreciable inhibition of bacterial growth. Compounds $4 a, 5 a, 5 b, 5 d, 5 e, 5 i$, and $5 j$ showed higher inhibition of fungal strain as compared with standard 
drug fluconazole. Based on the relationships between the structure of the substituted indanyl derivatives and their detected antimicrobial properties, it can be said that substituted indanyl derivatives showed varied biological activities. From in vitro antibacterial and antifungal studies (Tables 1 and 2), it was observed that a total of three compounds ( $4 a, 5 a$, and $5 b$ ) showed excellent results in both cases. Moreover, the presence of 5 and 6 position substituents causes a certain change of activity. Lipophilic alkoxy groups (methoxy and ethoxy) present on 5 and 6 positions of indane ring have enhanced the biological activity. Finally, it can be concluded that compounds $4 \mathrm{a}, 5 \mathrm{a}$, and $5 \mathrm{~b}$ have great potential as lead compounds for further structure-activity relationship studies in the search for a new antimicrobial agent.

\section{REFERENCES}

1. Patel A, Giles D, Basavarajaswamy G, Sreedhar C, Patel A. Synthesis, pharmacological evaluation and molecular docking studies of indanone derivatives. Med Chem Res 2012;21:4403-41.

2. Jubie S, Meena S, Ramaseshu KV, Jawahar N, Vijayakumar S. Synthesis and biological evaluation of some hydrazones and carbazones of indane-1,3-dione. Ind J Chem 2010;49:1261-3.

3. Patel VM, Bhatt ND, Bhatt PV, Joshi HD. Novel derivatives of 5, 6-dimethoxy-1-indanone coupled with substituted pyridine as potential antimicrobial agents. Arabian J Chem 2014. Available from: http:// www.sciencedirect.com/science/article/pii/S1878535214001610.

4. El-Sheshtawy HS, Abou Baker AM. Synthesis, structural, theoretical studies and biological activities of 3-(Arylamino)-2-phenyl- $1 H$-inden1-one Derivative. J Mol Struct 2014;1067:225-32.

5. Fadare OA, Akinpelu DA, Ejemubu H, Obafemi CA. 1-Indanone chalcones and their 2,4-dinitrophenylhydrazone derivatives: Synthesis, physicochemical properties and in vitro antibacterial activity. Afr J Pure Appl Chem 2014;8:68-77.

6. Jeyachandran M, Ramesh P. Synthesis, antimicrobial, anticoagulant activities of 2-(arylsulfonyl) indane-1, 3-diones. Org Chem Int 2011;47:1-6.

7. Albrecht R, Kessler HJ, Schroder E. Antimicrobial Indanones. US Patent 3671520, 1972; Filed March 27.

8. Tithi NS, Hossan MM, Bachar SC. Synthesis and biological activity evaluation of indan-1-carboxylic acid-3-semicarbazone and indan-1acetic acid-3-semicarbazone. Latin Am J Pharm 2015;34:116-23.

9. Karthik R, Jasmin SR, Sasikumar S, Kalyan SB, Christina AJ, Athimoolam $\mathrm{J}$, et al. Evaluation of anti-tubercular activity of some synthesised benz spiro-oxirane derivatives of indane-1,3-dione. Pharmacol Online 2008;2:176-91.

10. Saha DK, Das BK, Chandra S, Datta BK. Synthesis and antitubercular activity of some indanyl thiosemicarbazone derivatives. J Pharm Res Opin 2012;2:125-8.

11. Charris JE, Lobo GM, Camacho J, Ferrer R, Barazarte A, Dominguez JN, et al. Synthesis and antimalarial activity of (e) 2-(2-chloro-3-quinolinylmethyl idene)-5,7-dimethoxyindanones. Lett Drug Des Discov 2007;4:49-54.

12. Boettcher I, Elger W, Kirsch G, Siegmund F, Wachtel H. Nonsteroidal antiinflammatory agents 14 . Synthesis and pharmacological profile of 6-chloro-5-(cyclopentylmethyl)indan-1-carboxylic acid. J Med Chem 1984;27:413-4.

13. Sheridan H, Walsh JJ, Cogan C, Jordan M, McCabe T, Passante E, et al. Diastereoisomers of 2-benzyl-2, 3-dihydro-2-(1H-inden-2-yl)-1Hinden-1-ol: Potential anti-inflammatory agents. Bioorg Med Chem Lett 2009; 19:5927-30.

14. Sharma M, Ray SM. Aromatic amide derivatives of 5,6-dimethoxy-2,3dihydro-1H-inden(-1-yl)acetic acid as anti-inflammatory agents free of ulcerogenic liability. Bioorg Med Chem Lett 2007;17:6790-6.

15. Mandal SK, Ray SM. Synthesis and biological evaluation of (5,6-dialkoxy-3-oxo-2,3-dihydro-1 $H$-inden-1-yl)acetic acid esters as anti- inflammatory agents with much reduced gastrointestinal ulcerogenic potential. Indo Am J Pharm Res 2014;4:3796-807.

16. Mandal SK, Ray SM. Synthesis and biological evaluation of (6-chloro-3-oxo-2,3- dihydro-1H-inden-1-yl)acetic acid esters as antiinflammatory agents devoid of ulcerogenic potential at the tested dose level. Indo Am J Pharm Res 2014:4:343-50.

17. Saxena HO, Faridi U, Srivastava S, Kumar JK, Darokar MP, Luqman S, et al. Gallic acid-based indanone derivatives as anticancer agents. Bioorg Med Chem Lett 2008;18:3914-8.

18. Deady LW, Desneves J, Kaye AJ, Finlay GJ, Baguley BC and Denny WA. Positioning of the carboxamide side chain in 11-oxo-11hindeno[1,2-b]quinoline carboxamide anticancer agents: Effects on cytotoxicity. Bioorg Med Chem 2001;9:445-52.

19. Finkielsztein LM, Castro EF, Fabián LE, Moltrasio GY, Campos RH, Cavallaro LV, et al. New 1-indanone thiosemicarbazone derivatives active against BVDV. Eur J Med Chem 2008;43:1767-73.

20. Mostert S, Petzer A, Petzer JP. Indanones as high-potency reversible inhibitors of monoamine oxidase. Chem Med Chem 2015;10:862-73.

21. Huang L, Miao H, Sun Y, Meng F, Li X. Discovery of indanone derivatives as multi-target-directed ligands against Alzheimer's disease. Eur J Med Chem 2014;87:429-39.

22. Rai NP, Narayanaswamy VK, Shashikanth S, Arunachalam PN. Synthesis, characterization and antibacterial activity of 2-[1-(5-chloro2-methoxy-phenyl)-5-methyl-1H-pyrazol-4-yl]-5-(substitutedphenyl)-[1,3,4]oxadiazoles. Eur J Med Chem 2009;44:4522-7.

23. Budhwani S, SharmaS, Kalyane N. Synthesis of aryl (5-substituted benzofuran-2-yl) carbamate derivatives as antimicrobial agents. Asian J Pharm Clin Res 2017;10:377-81

24. Xu H, Fan LL. Antifungal agents. Part 4: Synthesis and antifungal activities of novel indole[1,2-c]-1,2,4-benzotriazine derivatives against phytopathogenic fungi in vitro. Eur J Med Chem 2011;46:364-9.

25. Hassan B, Soumya E, Sanae G, Saad IK. Evaluation of the antifungal activities of three essential oil components against Penicillium expansum spores. Int J Pharm Pharm Sci 2017;9:56-9.

26. Debnath B, Ganguly S. Synthesis of some novel (2-oxo-3-(arylimino) indolin-1-yl)-n-aryl acetamides and evaluation as antimicrobial agents. Toxicol Environ Chem 2015;97:741-53.

27. Techaoei S, Eakwaropas P, Jarmkom K, Khobjai W. Structure characterization and evaluation potential of antimicrobial extracts from Phellinus linteus against skin infectious pathogens, Staphylococcus epidermidis atcc12228 and propionibacterium acnes dmst14916. Int J Pharm Pharm Sci 2017;9:78-81. 